\title{
ANTIMICROBIAL APPROACHES FOR TEXTILES: FROM RESEARCH TO RETAIL
}

\section{${ }^{1}$ Mishra A. K., ${ }^{1}$ Wadhai V. S. and ${ }^{2}$ Bhandari P.R.}

1Sardar Patel Mahavidyalaya, Chandrapur (M.S) India

${ }^{2}$ Sevadal Mahila College Nagpur (M.S) India

Email: abhishekkmishra@hotmail.com

\begin{abstract}
The large surface and talent to retain moisture of textile structures helps microorganisms' growth that causes a variety of undesirable effects, not solely on the textile itself, however additionally on the use too. Due to the general public health awareness of the morbific effects on personal hygiene and associated health risks, over the previous few years, intensive analysis has been promoted so as to attenuate microbes' growth on textiles. Therefore, to impart associate antimicrobial ability to textiles, different approaches are studied, being principally divided into the inclusion of antimicrobial agents within the textile compound fibers or their affixation onto the chemical compound surface. This work principally intends to produce an outline of antimicrobial agents and coverings that may be performed to supply antimicrobial textiles, finishing approaches, which are under development or already commercially on the market within the types of isolated agents or textile fibers or fabrics.
\end{abstract}

Keywords: Textiles, Antimicrobial, Durability, Health impact

\section{Introduction:}

World fiber consumption has increased over several decades; from 1950 to 2008, the per capita consumption increased from $3.7 \mathrm{~kg}$ to $10.4 \mathrm{~kg}$, and through continuous development, it recorded in 2014 a demand of 55.2 million tons (122 billion pounds) of synthetic fibers, in addition to the natural fibers, including cotton and wool, which have a demand of 25.4 million tons $[1,2]$.This demand in 2016 reached to 99 million tons.[3]Fiber-based textile structures play an important role in several industries throughout the world, being used every day in order to meet different purposes [4,5]. Obviously, the technological advances of textiles are mainly recognized in clothing products; however, they also play important roles in other industries, such as food packaging, domestic home furnishings, automotive textiles, air filters, water purification systems, thermal and mechanical protection, sport equipment, medical devices, healthcare and hygienic applications [4-7].

Due to their large surface area and ability to retain moisture, textiles are known as being conducive to microorganisms' growth, such as bacteria and fungi, which can be found almost everywhere and are able to quickly multiply, depending on the moisture, nutrients and temperature levels [8].Some bacteria populations may double every 2030 min under ideal conditions $(36-40 \mathrm{C}, \mathrm{pH}$ 5-9), meaning that one single bacteria cell can increase to $1,048,576$ cells in just $7 \mathrm{~h}$ [9]. The microorganism's growth on textiles causes a range of undesirable effects, not only on the textile itself, but also on the user. These effects include the generation of unpleasant odor, reduction in mechanical strength, stains and discoloration and an increased likelihood of user contamination $[7,8]$. Therefore, due to the growing public health awareness of the pathogenic effects, over the last few years, intensive research and development have been promoted in order to minimize or even eliminate microbe's growth on textiles. The infections acquired in hospitals may be caused by several species, such as Escherichia coli, Staphylococcus aureus, Klebsiella pneumonia, Pseudomonas aeruginosa and Acinetobacter baumannii.

Therefore, as consumers are becoming increasingly aware of the implications on personal hygiene and the health risks associated with some microorganisms, the demand for antimicrobial textiles has presented a big increase over the last few years [8,10]. In a recent issue of Performance Apparel Markets, the report "Antimicrobial fibres, fabrics and apparel: innovative weapons against infection" referred to the global market for 
antimicrobial agents being expected to increase by about $12 \%$ each year between 2013 and 2018 [11].

In order to impart an antimicrobial ability to textiles, different approaches have been studied, which can be mainly divided into the inclusion of antimicrobial compounds in the polymeric fibers that can leach from the polymeric matrix, the grafting of certain moieties onto the polymer surface or the physical modification of the fibers' surface [7,12,13]. Regarding the antimicrobial compounds, different types have been used, such as quaternary ammonium compounds, triclosan, metal salts, polybiguanides or even natural polymers [8,12,13]. Any antimicrobial treatment performed on a textile needs to satisfy different requirements besides being efficient against microorganisms, but the main challenge is the concomitant requirement of non-toxicity to the consumer, namely cytotoxicity, allergy or irritation and sensitization $[8,12,13]$. In order to control the generation of resistant bacteria, not only the effective prevention and control of infections is extremely important, but also monitoring the practice and application of antimicrobial agents $[15,18]$.

This paper mainly intends to provide an overview of the different antimicrobial treatments that can be performed to produce antimicrobial textiles, using chemical or physical approaches, presenting an extensive listing of treatments under development and commercially available agents and textile fibers or fabrics. Afterwards, a detailed discussion is conducted about the environmental and public health impact due to the increasing application rates of antimicrobials agents.

\section{Textile Antimicrobial Treatments}

As already mentioned, an antimicrobial treatment performed on a textile needs to satisfy different requirements besides being efficient against microorganisms, namely to be suitable for textile processing; to present durability to laundering, dry cleaning and hot pressing; to present a favorable safety and environmental profile; and it should not harm the textile quality or appearance
$[8,10]$. Depending on the antimicrobial agent that is intended to be used, as well the fiber type, including the composition, structure and surface texture, there are different chemical and physical approaches that have been developed or that are under development to impart antimicrobial properties to the textile $[7,8]$. Some approaches are based on the use of specific antimicrobial agents, which in the case of synthetic fibers may be incorporated into the polymeric matrix $[8,12]$. Another possibility, which can be used for synthetic and natural fibers or any textile fabric, is the application, in the finishing stage, of antimicrobial agents on the material surface [8]. Depending on the approach used the antimicrobial textile may act by two different ways, by contact and/or diffusion. In the case of contact, the agent is placed on the fiber and does not disperse, so it will act just if the microorganism touches the textile surface. In the case of diffusion, the agent is on the fiber surface or in the polymeric matrix, and it will migrate from the textile to the external medium to attack the microorganisms [19].

A living microbe, a bacterium or fungus, presents an outermost cell wall composed of polysaccharides, which maintains the integrity of cellular components and protects the cell from the extracellular environment $[8,20,21]$. Beneath the cell wall is a semipermeable membrane, which encloses the intracellular organelles, enzymes, which are responsible for chemical reactions within the cell, and nucleic acids, which store all of the genetic information. The survival and growth of microorganisms depend on the cell integrity and, consequently, proper function. Therefore, an antimicrobial chemical agent or material may be classified according to the mode of action against cells' function or integrity. If their effect happens just due to the inhibition of cell growth, they present a biostatic effect, but if they can kill the microorganisms, their effect is called biocidal [8,22].

\section{Antimicrobial Agents}

Most of the antimicrobial agents used in commercial textiles are biocides acting in different ways according to their chemical 
and structural nature and affinity level to certain target sites within microbial cells. Those different modes of action may be [2022]:

- Damage or inhibition of cell wall synthesis, which is critical for the life and survival of bacterial species;

- Inhibition of cell membrane function, which is an important barrier that regulates the intra- and extra-cellular flow of substances, could result in the leakage of vital solutes for the cells' survival;

- Inhibition of protein synthesis, which is the basis of cell enzymes and structures, consequently leading to the death of the organism or the inhibition of its growth and multiplication;

- Inhibition of nucleic acid synthesis (DNA and RNA) due to the binding of some antimicrobial agents to components involved in the process of DNA or RNA synthesis. This inhibition interferes with normal cellular processes, compromising microbes' multiplication and survival;

- Inhibition of other metabolic processes, for instance the disruption of the folic acid pathway, which is essential for bacteria to produce precursors important for DNA synthesis.

\section{Metals and Metallic Salts}

Non-essential metals can be extremely toxic to most microbes at exceptionally low concentrations, either in the free state or in compounds. Due to their biocidal activity, different metal, oxide or salt compounds, mostly based on silver, but also on copper, zinc and titanium, have been widely used as antimicrobial agents in textiles for agriculture, healthcare and other industries. $[7,8,9]$. Their biocidal effect, depending on the metal, can be triggered by the metal reduction potential and/or by the metal donor atom selectivity and/or speciation (the formation of new species in the course of evolution). Therefore, redoxactive essential metals can act as catalytic cofactors in a wide range of cell enzymes, either generating or catalyzing reactive oxygen species, which can induce an oxidative stress, damaging cellular proteins, lipids and DNA. Metal nanoparticles are actually presented as an interesting approach, as they present a higher surface area and can dissolve faster in a given solution when compared to larger particles, releasing therefore a higher amount of metal ions and presenting a stronger antimicrobial effect. Moreover, another advantage is that they are easily embedded into fibers' polymeric matrices [13,25].

\section{Chitosan}

Chitosan is a natural and hydrophilic copolymer, which results from the deacetylation of chitin extracted from the exoskeleton of crustaceans, like crabs and shrimps, and even from the cell walls of several fungi. It is composed of two monomeric units, D-glucosamine and $\mathrm{N}$ acetyl-D-glucosamine, linked by a (1-4)glycosidic bond $[13,26]$. This linear polysaccharide has been widely studied for textiles finishing, mostly for medical applications, due to its biocompatibility, non-toxicity, non-carcinogenicity and antimicrobial activity $[14,27,28]$. It is mostly used to finish cotton, polyester and wool fibers, and it has presented an antimicrobial activity against a wide spectrum of microorganisms, including fungi, algae and some bacteria $[8,29,30]$. It is generally accepted that the first step is always based on the interaction between the primary amine group's positive charges and the negative charges on the microbes' surface. Then, in the case of low Mw watersoluble chitosan, it can penetrate the cell wall, combine with DNA and inhibit the synthesis of mRNA, preventing protein synthesis $[13,25]$. The antimicrobial effect of the complexes was much higher than in the case of free chitosan or metal salts. The authors concluded that the phenomenon was due to the stronger positive charge after complexation [28]

\section{Natural-Based Antimicrobial Agents}

Due to the emergence of the antibiotic resistance of pathogenic bacteria, antimicrobial compounds extracted from herbs and plants have also been extensively studied as an alternative therapeutic strategy to combat microbial growth in textiles such as Honey, Curcumin , Henna etc. $[16,17,31]$. The main advantage of using these natural compounds for antimicrobial purposes is that they do not 
exhibit the side effects often associated with synthetic chemicals. Until now, no reports of antimicrobial resistance to these natural chemicals have been published. Despite the lack of research about the mechanistic basis of their antimicrobial action, it is supposed that the microbial resistance is prevented probably by their multiple action mechanisms, avoiding the selection of resistant bacteria strains [16,17,32]. Moreover, these substances may present an efficient antimicrobial effect, with safety, easy availability, nontoxicity to skin and being environmentally-friendly [16,17]

\section{Experimental discussions:}

Finishes were applied on cotton initially at specific concentration using pad-dry-cure to develop antibacterial activity that would be more durable for antimicrobial performance. AATCC test method 147 was used for qualitative evaluation for finished fabrics with repeated laundering upto five cycles. The initial concentrations selected for chitosan (silver coated) were $20 \mathrm{~g} / \mathrm{L}$ respectively at $\mathrm{pH} 6$.. Based on these results, application method was selected accordingly for each agent that showed highest levels of antimicrobial performance at optimum concentrations. Washing durability of each agent for its optimum concentrations was evaluated. Physical properties of finished cotton as well as antimicrobial performance up to five laundering cycles were evaluated using AATCC 135 Test Method.

The finished cotton fabrics were evaluated for antimicrobial activity against $S$. aureus and E. coli after each laundering cycle up to five times. The results for all five agents pad dry cure application methods are presented in Table 2. Antimicrobial activity was recorded with Chitosan (Silver Coated) $(20 \mathrm{~g} / \mathrm{L})$, Metallic Salts (Tio2 \& $\mathrm{ZnO})(10 \mathrm{~g} / \mathrm{L})$, Curcumin $(40 \mathrm{~g} / \mathrm{L})$ and Honey $(50 \mathrm{~g} / \mathrm{L})$ against both bacteria without laundering. CtsAg composite, TiO2 and $\mathrm{ZnO}$ nanoparticles retained its antimicrobial activity against both E.coli and S.aureus until $5^{\text {th }}$ laundering cycle. Silver coated Chitosan (Cts Ag) at $20 \mathrm{~g} / \mathrm{L}$ showed inhibition zone against both bacteria even after the $25^{\text {th }}$ washing.

All antibacterial agents are applied on the surface of the cotton fabric. Due to the low molecular weight of silver, Tio2 and $\mathrm{ZnO}$ nanoparticles they can leach out forming the zone of inhibition. Chances are that these agents remain coated on the surface as well as get trapped inside the cellulose convolutions due to application of force during padding and act until their reservoir ends with usage and repeated launderings. 
Table-1. Zone of inhibition after each washing cycles (in $\mathrm{mm}$ )

\begin{tabular}{|c|c|c|c|c|c|c|c|c|c|c|}
\hline \multirow[t]{2}{*}{ No. of Washings } & \multicolumn{2}{|c|}{ CHITOSAN +SILVER } & \multicolumn{2}{|c|}{ ZnO } & \multicolumn{2}{|c|}{ TiO2 } & \multicolumn{2}{|c|}{ Honey } & \multicolumn{2}{|c|}{ Turmeric } \\
\hline & E.coli & S.aureus & E.coli & S.aureus & E.coli & S.aureus & E.coli & S.aureus & E.coli & S.aureus \\
\hline after 0 wash & 36 & 44 & 34 & 52 & 33 & 42 & 24 & 27 & 34 & 48 \\
\hline 5 washings & 32 & 41 & 30 & 48 & 29 & 38 & 15 & 22 & 22 & 34 \\
\hline 10 washings & 24 & 35 & 26 & 44 & 22 & 32 & 6 & 15 & 10 & 22 \\
\hline 15 washings & 12 & 20 & 22 & 26 & 20 & 25 & 0 & 7 & 4 & 13 \\
\hline 20 washings & 8 & 14 & 11 & 17 & 14 & 18 & 0 & 0 & 0 & 6 \\
\hline 25 washings & 0 & 6 & 4 & 7 & 7 & 10 & 0 & 0 & 0 & 0 \\
\hline
\end{tabular}

Graph-1. Zone of Inhibition after washings

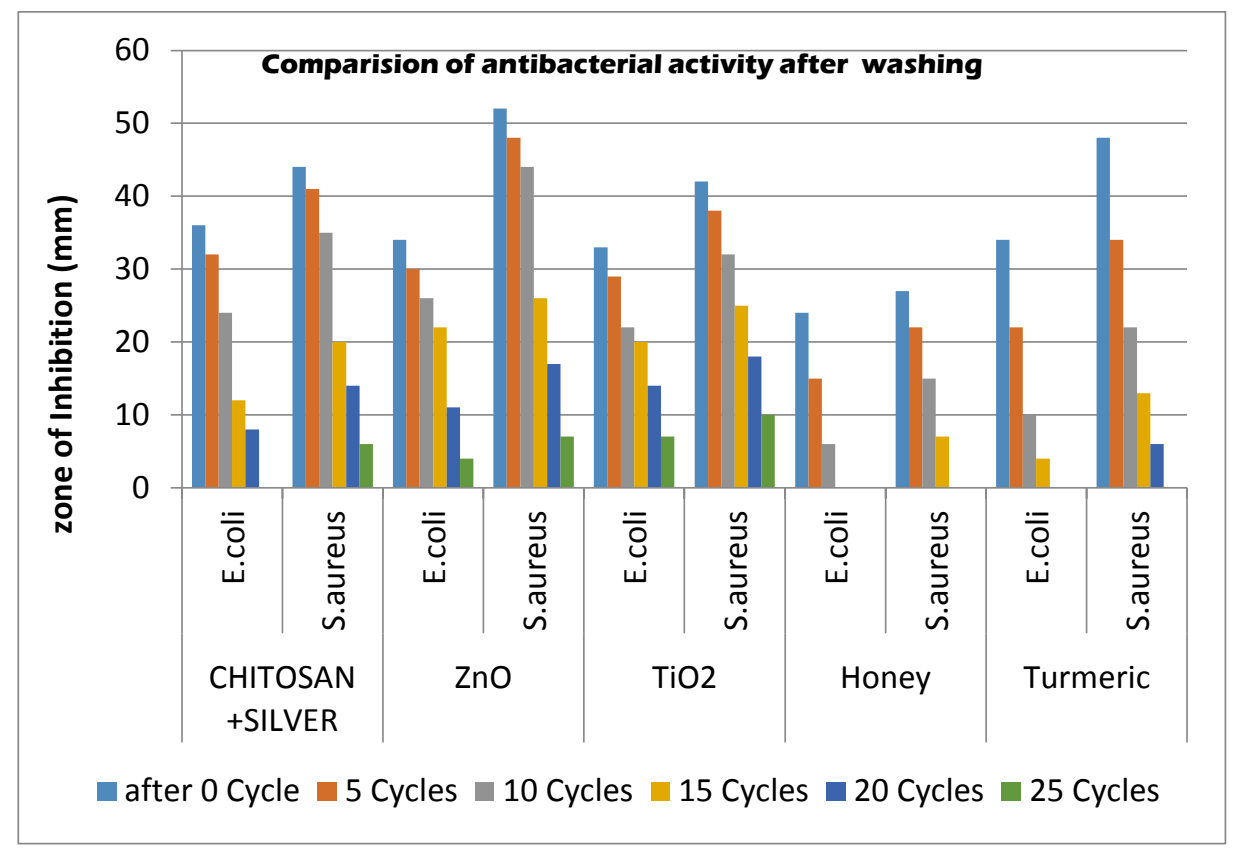

From Table 1 the launderability results for pad-dry cure methods for all five agents against both microbes showed that these finishes didn't require any specific application technique and could be easily applied by pad-dry method. Honey at 50 g/L show comparatively poor activity against both bacteria. Loss in antimicrobial activity was obtained after first laundry cycle to a great extent. The ZOI reduces from $24 \mathrm{~mm}$ for E.coli and $27 \mathrm{~mm}$ for S.aureus prewashing to nil for both of the bacterias after 3 cycles of washing i.e. 15 washings. This could be due to removal of a superficial layer of Honey from the fabric. Similarly methanol extracted Curcumin (30 $\mathrm{g} / \mathrm{L})$ shows a better result and large inhibition zone against gram positive bacteria. Its pre-laundry zone of inhibion was found to be $48 \mathrm{~mm}$ as comparative to E.coli (gram negative)having zone of inhibition $34 \mathrm{~mm}$ respectively. Though the washing durability was found to be weak as compared to other agents.

\section{Environmental and Health Impact of Antimicrobial Agents}

Regarding the development of antimicrobial treatments for textiles, the advantages of the chosen antimicrobial agent, such as biocide effectiveness, should outweigh the potential environmental consequences and costs of its usage. As environmental benefits, antimicrobial-treated textiles may present a prolonged useful period of textile wear, the potential for less frequent laundry cycles, lower washing temperatures and a 
reduction of detergent consumption in each wash cycle. The most desirable agents are the ones that are simultaneously efficient at low dosing levels and that present durable functionality. The environmental impact of the antimicrobial textiles mainly using triclosan, Silver nanoparticles, QAC and other synthetic compounds which is a critical global concern, is related to the textile substrate material, antimicrobial compound production, textile treatment processes and also the subsequent use and disposal of the product $[10,34]$.

When antimicrobials are released from textiles, if they are not removed in the waste water treatment, they may end up in the aquatic environment. Several studies have revealed that large portions of silver (including metallic Ag and Ag nanoparticles) and triclosan are effectively removed during waste water treatment, namely 85\%-99\% and $90 \%-96 \%$, respectively [10]. QACs, for instance, are generally referred to as "hard antibacterial agents" as they are poorly metabolized and mainly excreted in a nonmetabolized form. The biodegradability of QACs is generally considered as poor; however, considerable variation has been observed depending on the concentration of the substance [27]. Triclosan, for instance, is degradable when subjected to aerobic conditions, but it may be persistent under anaerobic conditions. The triclosan photolysis half-life, which is the main degradation process, has been estimated as about $41 \mathrm{~min}$ and the half-life in lake water as about 10 days [10,35] Some studies revealed that nano-Ag may be immobilized by the formation of stable sulfide complexes, resulting in silver sulfide, which is very insoluble and much less toxic and bioavailable than dissolved silver. Therefore, the formation of silver sulfide would significantly decrease the risk of silver-based compounds in the aquatic environment $[10,36]$.

Moreover, the introduction of rigorous ecological legislation is forcing companies to consider not only the issue of industrial waste disposal, but also the possible replacement of conventional processes with new approaches that can provide equal or even higher efficiency and lower environmental impact. The use of plasma technologies for pre-treatments, for instance, is increasingly replacing conventional wet chemical applications, not only for economic considerations, but also for the ecological advantages. The dry plasma treatment does not employ harmful chemical solutions (solvent-free process) and does not produce contaminated water or create mechanical hazards for treated fabrics [37]. Another environment-friendly approach that is becoming increasingly used in textiles is the promotion of specific reactions catalyzed by enzymes. Among the most used enzymes for polymer modifications are, for instance, glycosidases, proteases, lipases and laccase.

Besides the "green" technologies, researchers have also studied the usage of "green" modifying antimicrobial agents, such as natural biopolymers extracted from animals or plants, namely chitosan, cyclodextrin, sericin, alginate and others, which are renewable and have the potential to be a key resource in the development of sustainable bioactive textiles [38]. Khurshid et al. have developed an ecofriendly natural antimicrobial textile finish for cotton, using extracted Aloe vera gel mixed with an active substance of Neem plants. Wadhai et.al had reported positive and increased antibacterial activity with the combination of natural antimicrobial agents with metallic salts nanoparticles. This hybrid combination presented an effective antibacterial and antifungal activity and even good durability to washing [33].

The type of action of the antimicrobial agent, by diffusion or contact, its concentration in the textile, the exposure routes and the frequency of use will influence the extent to which humans may be exposed to the textile. Some parameters usually evaluated to assess the risk profile of an antimicrobial agent associated with a textile are the toxicity (acute and chronic), skin sensitization and irritation and the disturbance of skin ecology. For all of the antimicrobial agents there are no conclusions regarding their skin toxicity and effects on human health. In the case of metallic compounds, $\mathrm{Zn}$ (zinc 
nanoparticles), for instance, may present some risks of neurotoxicity [10]. Regarding $\mathrm{Ag}$ ions, which are non-specific in action as other biocides, they may interact with skin flora, causing the detachment of the cytoplasmic membrane from the cell wall of healthy bacteria, weakening the skin defense barrier [40,41].

In order to influence the antimicrobials' use pattern and the market share of particular compounds, some changes in the applicable regulation should be performed. Thus, the antimicrobial use pattern in textiles would be modulated according to the specific application and need, resulting in a significant reduction of antimicrobials' flow to the environment. Though the washing durability is less and weak as compared to other antibacterial agents but the naturally originated agents such as Honey, Curcumin, Aloe Vera, Neem etc. should be used, either individually or in combination with other synthetic antibacterial. The regulatory assessment of single antimicrobial substances should be based on a broader perspective and knowledge of antimicrobials, taking into account the risks and benefits of their use compared to alternative antimicrobial substances [10,39].

\section{Conclusions:}

In the last few years, the customer's desire for comfort, hygiene and well-being, concerning odor control and microorganisms protection, has created a large and rapidly increasing market for the expansion of antimicrobial textiles. Despite the advantages associated with the antimicrobial textiles, the bacterial resistance promoted by the agents, their toxic breakdown products and the consequent risks to human health and environment balance have been a great concern. The long-term benefits and potential problems associated with antimicrobial textiles should be simultaneously considered and closely monitored to avoid the problems overpassing the benefits. Therefore, in the future, more efforts must be done by researchers and manufacturers in order to develop more environment-friendly techniques and to promote the usage of "green" agents, namely natural-based compounds, which have revealed potential antimicrobial activity without harmful effects to the surrounding medium. Another future suggestion is to explore the agents' micro-encapsulation. This could improve their durability on the textile matrix and simultaneously improve the human and environment safety level

\section{References:}

FAO (Food and Agriculture Organization of the United Nations) and ICAC (Cotton Advisory Committee).A Summary of the World Apparel Fiber Consumption Survey 2005-2008; Food and Agriculture Organization of the United Nation, International Cotton Advisory Committee: Rome, Italy, 2011.

Textile World. Man-Made Fibers Continue to Grow. Available online: http://www.textileworld.com/textileworld/fiber-world/2015/02/man-madefibers-continue-to-grow/ (accessed on 3 February 2015).

ICAC, CIFRS, The Fiber Year, The Fiber Organon, Lenzing estimates

Collier, B.J.; Tortora, P.G. Understanding Textiles; Prentice Hall: Englewood Cliffs, NJ, USA, 2001.

Hollen, N.R.; Saddler, J.; Langford, A.L. Textiles; Macmillan: New York, NY, USA, 1979.

Singleton, J. The World Textile Industry; Routledge: London, UK, 2013.

Shahidi, S.; Wiener, J. Antimicrobial Agents-Chapter 19: Antibacterial Agents in Textile Industry; InTech: Rijeka, Crotia, 2012.

Gao, Y.; Cranston, R. Recent advances in antimicrobial treatments of textiles. Text. Res. J. 2008, 78, 60-72.

Zanoaga, M.; Tanasa, F. Antimicrobial reagents as functional finishing for textiles intended for biomedical applications. I. Synthetic organic compounds. Chem. J. Mold. 2014, 9, 14-32.

Windler, L.; Height, M.; Nowack, B. Comparative evaluation of antimicrobials for textile applications. Environ. Int. 2013, 53, 62-73. [CrossRef] [PubMed]

Intelligence, $\mathbf{T}$. Demand for Antimicrobial Fibres, Textiles and Apparel Is Set for Strong Growth Performance Apparel Markets. 2014. Available online: http://www.innovationintextiles.com/dema nd-for-antimicrobial-fibres-textiles-andapparel-is-set-for-strong-growth/ (accessed on 20 December 2015). 
Bshena, O.; Heunis, T.D.; Dicks, L.M.; Klumperman, B. Antimicrobial fibers: Therapeutic possibilities and recent advances. Future Med. Chem. 2011, 3, 1821-1847. [CrossRef] [PubMed]

Simoncic, B.; Tomsic, B. Structures of novel antimicrobial agents for textiles-A review. Text. Res. J. 2010, 80, 1721-1737. [CrossRef]

Bartels, V. Handbook of Medical Textiles; Elsevier: Cambridge, UK, 2011.

Weinstein, R.A. Controlling antimicrobial resistance in hospitals: Infection control and use of antibiotics.Emerg. Infect. Dis. 2001, 7, 188-192. [CrossRef] [PubMed]

Upadhyay, A.; Upadhyaya, I.; KollanoorJohny, A.; Venkitanarayanan, $K$. Combating pathogenicmicroorganisms using plant-derived antimicrobials: A minireview of the mechanistic basis. BioMed Res. Int.2014, 2014, 761741. [CrossRef] [PubMed]

Savoia, D. Plant-derived antimicrobial compounds: Alternatives to antibiotics. Future Microbiol. 2012, 7,979-990. [CrossRef] [PubMed]

Nwosu, V.C. Antibiotic resistance with particular reference to soil microorganisms. Res. Microbiol. 2001, 152,421-430. [CrossRef]

Shishoo, R. Plasma Technologies for Textile; Elsevier: Cambridge, UK, 2007.

Michigan State University. Antimicrobial Resistance Learning Site; Michigan State University: East Lansing,MI, USA, 2011.

Glazer, A.N.; Nikaido, H. Microbial Biotechnology: Fundamentals of Applied Microbiology; Cambridge University Press: Cambridge, MA, USA, 2007.

Rahman, M.A.; Ahsan, T.; Islam, S. Antibacterial and antifungal properties of the methanol extract from the stem of argyreia argentea. Bangladesh J. Pharmacol. 2010, 5, 41-44. [CrossRef]

Russell, A.D.; Furr, R.; Maillard, J.-Y. Microbial susceptibility and resistance to biocides. ASM News 1997, 63, 481-487

Kegley, S.; Hill, B.; Orme, S.; Choi, A. Pan Pesticide Database, Pesticide Action Network, North America (San Francisco, CA, 2010); Pesticide Action Network: Oakland, CA, USA, 2010.

Palza, H. Antimicrobial polymers with metal nanoparticles. Int. J. Mol. Sci. 2015, 16, 2099-2116. [CrossRef][PubMed]

Morais, D.; Rodrigues, M.; Lopes, M.; Coelho, M.; Mauricio, A.C.; Gomes, R.; Amorim, I.; Ferraz, M.;Santos, J.; Botelho, C. Biological evaluation of alginate-based hydrogels, with antimicrobial features by ce incorporation, as vehicles for a bone substitute. J. Mater. Sci. Mater. Med. 2013, 24, 2145-2155. [CrossRef][PubMed]

Badawy, M.E.; Rabea, E.I. A biopolymer chitosan and its derivatives as promising antimicrobial agents against plant pathogens and their applications in crop protection. Int. J. Carbohydr. Chem. 2011, 2011, 460381.[CrossRef]

Wang, X.; Du, Y.; Fan, L.; Liu, H.; Hu, Y. Chitosan-metal complexes as antimicrobial agent: Synthesis, characterization and structure-activity study. Polym. Bull. 2005, 55, 105-113. [CrossRef]

Knitte1, D.; Schollmeyer, E. Chitosans for permanent antimicrobial finish on textiles. Lenzing. Ber. 2006, 85,124-130.

Lim, S.-H.; Hudson, S.M. Application of a fiber-reactive chitosan derivative to cotton fabric as an antimicrobial textile finish. Carbohydr. Polym. 2004, 56, 227-234. [CrossRef]

Shahid, M.; Mohammad, F. Perspectives for natural product based agents derived from industrial plants in textile applications-A review. J. Clean. Prod. 2013, 57, 2-18. [CrossRef]

Cowan, M.M. Plant products as antimicrobial agents. Clin. Microbiol. Rev. 1999, 12, 564-582. [PubMed]

Wadhai V.S.;Mishra A.K.;Sontakke R.P. Study of antimicrobial finishes on textiles using natural herbal extract. IJRBT. Issue 3, Vol.8, May 2015.

Slater, K. Environmental Impact of Textiles: Production, Processes and Protection; Woodhead Publishing: Cambridge, UK, 2003; Volume 27.

United States Environmental Protection Agency. Reregistration Eligibility Decision for Triclosan. 2008. Available online: https://archive.epa.gov/pesticides/reregistr ation/web/pdf/2340red.pdf (accessed on 22 January 2016).

Eckelman, M.J.; Graedel, T. Silver emissions and their environmental impacts: A multilevel assessment. Environ. Sci. Technol. 2007, 41, 6283-6289. [CrossRef] [PubMed]

Kan, C.-W. A Novel Green Treatment for Textiles: Plasma Treatment as a Sustainable Technology; CRC Press: Boca Raton, FL, USA, 2014

Shahid, M.; Mohammad, F. Green chemistry approaches to develop antimicrobial textiles based on sustainable biopolymers-A review. Ind. Eng. Chem. Res. 2013, 52, 5245-5260. [CrossRef] 
World Health Organization. Antimicrobial Resistance: Global Report on Surveillance; WHO: Geneva, Switzerland, 2014.

Lansdown, A. Silver in health care: Antimicrobial effects and safety in use. Curr. Probl. Dermatol. 2006, 33, 17-34. [PubMed]
Wollina, U.; Abdel-Naser, M.; Verma, S. Skin physiology and textiles-consideration of basic interactions. Curr. Probl. Dermatol. 2006, 33, 1-16. [PubMed] 